\title{
Silylium Ion Catalyzed C-H Arylation of Hydrocarbons
}

Gategory

Organo- and

Biocatalysis

\section{Key words}

arylation

hydrocarbons

phenyl cation

silylium ion

$$
R^{1}=\mathrm{Ar}, \mathrm{Alk}, \mathrm{Hal} \quad \mathrm{R}^{2}=\mathrm{Ph}, \mathrm{Alk}
$$

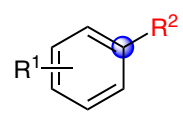

18 examples $29-99 \%$ yield

\section{Selected examples:}<smiles>Brc1ccc(Pc2ccccc2)cc1</smiles>

$56 \%$ GC yield<smiles>c1ccc(-c2cccc3ccccc23)cc1</smiles>

$49 \%$ isolated yield<smiles>CCCCCOc1ccccc1</smiles>

$42 \%$ GC yield $(\alpha / \beta / \gamma=30: 10: 2)$<smiles>COc1cccc2ccccc12</smiles>

$32 \%$ isolated yield

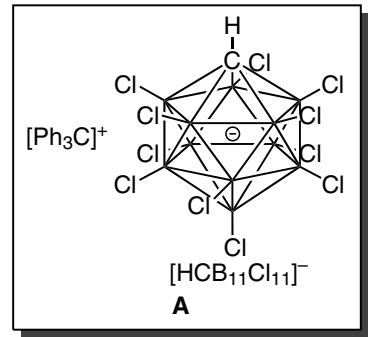

Proposed catalytic cycle:

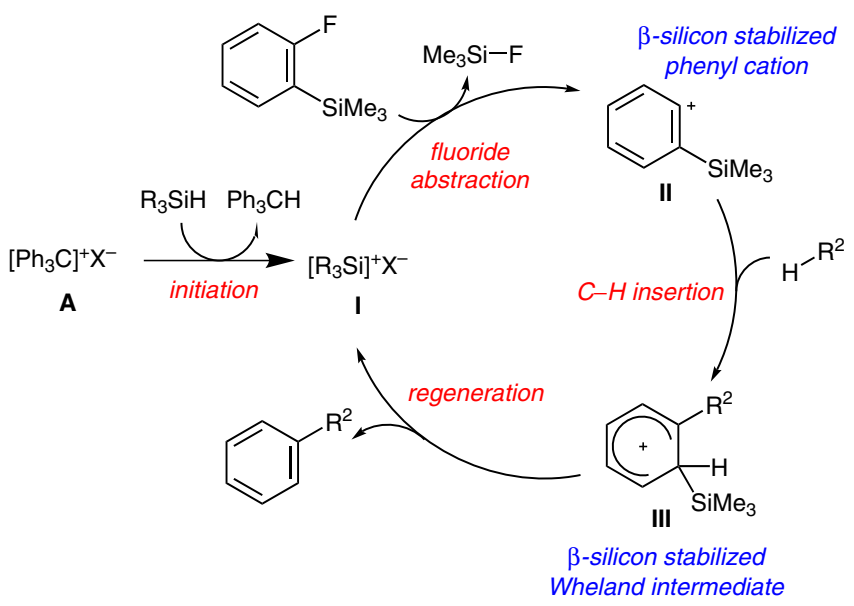

Significance: The Nelson group reports a silylium ion catalyzed arylation of $\mathrm{C}\left(\mathrm{sp}^{2}\right)-\mathrm{H}$ and $\mathrm{C}\left(\mathrm{sp}^{3}\right)-\mathrm{H}$ bonds. By employing 2-5 mol\% of precatalyst $\mathbf{A}$ in the presence of a trialkylsilane initiator, various aliphatic and aromatic hydrocarbons were arylated with variously functionalized trimethylsilyl fluorobenzenes.

SYNFACTS Contributors: Benjamin List, Lucas Schreyer Synfacts 2017, 13(06), 0645 Published online: 16.05.2017 DOI: $10.1055 / \mathrm{s}-0036-1590436$; Reg-No.: B04017SF
Comment: Previously, catalytic reactions involving highly reactive phenyl cation equivalents were limited to intramolecular transformations. The authors describe the formation of a $\beta$-siliconstabilized phenyl cation (equivalent) II, which is proposed to subsequently undergo intermolecular insertion into the $\mathrm{C}-\mathrm{H}$ bond of a hydrocarbon present in large excess. Desilylation of the resulting Wheland intermediate furnishes the product and regenerates the catalytically active species $\mathbf{I}$. 